\title{
Integração Entre os Estados Brasileiros Produtores de Etanol ${ }^{1}$
}

\author{
Marcelo Lopes de Moraes² e Mirian Rumenos Piedade Bacchi ${ }^{3}$
}

Resumo: O objetivo deste artigo é analisar as relações de longo prazo do preço do etanol do segmento produtor nos estados do Paraná, São Paulo, Minas Gerais, Goiás, Mato Grosso e Mato Grosso do Sul (região Centro-Sul) e Alagoas e Pernambuco (região Norte-Nordeste), possibilitando identificar a dinâmica do processo de formação de preço no mercado doméstico. Na análise foram utilizados dados mensais do período de abril de 2008 a março de 2013 e a metodologia foi o modelo de cointegração de Johansen (1988) e testes sobre os parâmetros $\beta$ e $\alpha$ do vetor de cointegração, possibilitando analisar relações de integração, perfeitas ou não. Os resultados mostram que os estados de São Paulo, Paraná, Minas Gerais e Goiás são perfeitamente integrados entre si, além de todos apresentarem relações, embora não perfeitas, com os estados da região Norte-Nordeste e também com o estado de Mato Grosso. Os estados da região Norte-Nordeste são perfeitamente integrados.

Palavras-chaves: Etanol; Preços; Integração de mercados.

Abstract: The objective of the present study is to analyze the long-run relation of ethanol price in different producing states in Brazil: Paraná, São Paulo, Minas Gerais, Goiás, Mato Grosso and Mato Grosso do Sul (Central-South) and Alagoas and Pernambuco (North-Northeast), to identify the dynamic process of price establishment. Monthly data from April 2008 to March 2013 were used with the methodology of cointegration model described by Johansen (1988) and tests on $\beta$ and $\alpha$ parameters of cointegration vector to analyze perfect integration and integration relations, although non perfect integrated. The results showed that São Paulo, Paraná, Minas Gerais and Goiás are perfectly integrated. Moreover, these states showed non perfect integration with the states of North-Northeast and Mato Grosso. The states of North-Northeast region are perfectly integrated.

Key-words: Ethanol; Prices; Market integration.

DOI - http://dx.doi.org/10.1590/1234-56781806-9479005304003

Classificação JEL: C00, C3, C33.

1. Data de submissão: 20 de maio de 2014. Data de aceite: 11 de novembro de 2015 .

2. Universidade Estadual do Oeste do Paraná (Unioeste). Francisco Beltrão, Paraná, Brasil. E-mail: marcelopesmoraes@gmail.com

3. Escola Superior de Agricultura "Luiz de Queiroz" (Esalq) da Universidade de São Paulo (USP). Piracicaba, São Paulo, Brasil. E-mail: mrpbacch@usp.br_ 


\section{Introdução}

No Brasil, durante aproximadamente 400 anos, o principal subproduto extraído da cana-de-açúcar foi o açúcar. No entanto, independente de choques externos de petróleo ou questões ambientais, o álcool-motor passou a ser um subproduto da cana-de-açúcar no início do século XX.

A primeira iniciativa de divulgação do álcool no Brasil foi promovida pela Sociedade Nacional da Agricultura (SNA) que, em outubro de 1903, realizou a Exposição Internacional de Aparelhos a Álcool e, paralelamente, o Congresso Internacional de Álcool, com o objetivo de apresentar propostas para ampliar o uso do produto na matriz energética, destacando a sua utilização em veículos automotores (SNA, 1904 apud DUNHAM, FLECK e BOMTEMPO, 2011).

Em 1922, o presidente Epitácio Pessoa (19201922) criticou a dependência brasileira da gasolina importada e propôs a sua substituição pelo álcool, prevendo que efeitos positivos seriam sentidos pela indústria canavieira (MARCOLIN, 2008).

A crise de 1929 teve influência positiva na formação do mercado interno de álcool combustível, pois afetou o mercado externo, que era o principal destino do açúcar brasileiro. Houve quedas expressivas nos preços do mercado internacional e, no mercado interno, a demanda se reduziu. Em 1931, Getúlio Vargas, por meio do
Decreto n. 19.717/31, definiu compulsoriamente o uso da mistura de $5 \%$ de álcool anidro na gasolina importada ${ }^{4}$ e, no mesmo ano, foi criada a Comissão de Estudos sobre Álcool-Motor (Ceam) (DUNHAM, FLECK e BOMTEMPO, 2011). Em 1933, o Instituto de Açúcar e Álcool (IAA), que tinha entre seus objetivos o estímulo à produção e consumo de álcool, passou a operar. Szmrecsányi (1979) cita que, a partir de década de 19305 , "o álcool passou a ganhar nova importância, deixando de constituir um simples subproduto, para tornar-se um fator de equilíbrio da agroindústria canavieira [...]" (p. 170).

Com a eclosão da II Grande Guerra, segundo Moraes (2000), a produção de álcool anidro aumentou devido à escassez da gasolina, que era quase que totalmente importada. Leis e decretos que vigoraram entre 1937 e 1941 incentivaram a produção de álcool anidro e, em 1941, o teor de mistura desse produto na gasolina passou para 20\%. Em 1942, através de um decreto-lei, "a indústria alcooleira foi declarada de interesse nacional" (MORAES, 2000, p. 49) e foram garantidos, por quatro anos, preços mínimos para o álcool e suas matérias-primas necessárias à fabricação.

Com o final da guerra, havia oportunidade de o Brasil aumentar sua participação no

4. Para os autores, esse decreto pode ser considerado o marco inicial da produção de etanol em larga escala no Brasil.

5. Mais precisamente em 1933, com a criação do IAA. 
mercado mundial de açúcar (SZMRECSÁNYI, 1979) e, assim, o álcool volta a ser um produto secundário para o setor canavieiro. Mas um fator alterou a posição desse produto dentro da indústria e a maneira de o Estado atuar no impulso à produção e consumo: os dois choques do petróleo da década de 1970. Os choques do petróleo da década de 1970 incentivaram, em âmbito mundial, a busca por fontes alternativas de energia e o Brasil, utilizando toda estrutura canavieira que vinha sendo usada principalmente na produção de açúcar, lança o Programa Nacional do Álcool (Proálcool).

No final da década de 1990 o Programa entra em colapso, sendo a queda do preço do petróleo o principal fator responsável pela crise. Além do contrachoque do preço do petróleo, o aumento expressivo da frota de carros a álcool resultou em momentos de desabastecimento em 1989, afetando a confiança do consumidor. Na segunda metade da década de 1990 era praticamente inexistente a produção dos carros com motores a álcool no País.

Um novo e grande impulso ao etanol no Brasil ocorre em 2003 com o lançamento dos carros flex-fluel. No ano de lançamento, apenas $2,8 \%$ dos carros e comerciais leves ${ }^{6}$ licenciados possuíam essa tecnologia e, em 2012, tal categoria representou $87 \%$ dos licenciamentos desses veículos (ANFAVEA, 2013). Essa nova fase resultou no aumento da produção de cana-de-açúcar e, consequentemente, na importância do setor sucroenergético na economia nacional.

$\mathrm{O}$ aumento da produção de cana-de-açúcar ocorreu primeiramente nas áreas tradicionais. Quando se trata de combustível, a localização próxima do mercado consumidor é mais eficiente do ponto de vista econômico devido aos custos e transporte (logística e armazenagem). Nesse contexto, Castro et al. (2010) explica que os três estados do Centro-Oeste não foram contemplados pelo Proálcool por estarem distante dos mais importantes centros consumidores, além de possuírem menor aptidão agrícola na época. No

6. Considera os automóveis e comerciais leves. entanto, a região Centro-Oeste, ignorada inicialmente, passa a ser alvo da nova expansão da atividade canavieira?

Nesse cenário de expansão da atividade canavieira para outras regiões que não as tradicionais ${ }^{8}$, o objetivo desse estudo é analisar as relações de longo prazo do preço do etanol do segmento produtor nos diferentes estados do Brasil: Paraná, São Paulo, Minas Gerais, Goiás, Mato Grosso e Mato Grosso do Sul (região Centro-Sul) e Alagoas e Pernambuco (região Norte-Nordeste), o que torna possível identificar a dinâmica do processo de formação de preço no mercado doméstico. Tal proposta fundamenta-se na hipótese de que os preços desses estados possam ser integrados, mesmo que não perfeitamente, dada à existência de arbitragem. Se a hipótese não for rejeitada, pode-se considerar o mercado de etanol como de abrangência nacional.

Estudos dessa natureza, que permitem identificar o mercado relevante ${ }^{9}$ para o produto em questão, possibilitam auxiliar órgãos responsáveis pela defesa da concorrência, como o Conselho Administrativo de Defesa Econômica (Cade) a emitir parecer sobre fusões e aquisições do setor, além de ser uma ferramenta, somada a outras, útil para a definição de políticas públicas no que diz respeito à tributação. Pode-se, ainda, fazer inferências sobre arbitragem considerando diferentes regiões produtoras.

7. Para mais, ver Shikida (2013).

8. Nos quase 500 anos de história da cana-de-açúcar no Brasil, é natural que em fases de aumento da produção novas áreas surjam, sendo inicialmente denominadas de regiões não tradicionais e, com o passar do tempo, torna-se uma região tradicional: pode-se dizer que o estado de São Paulo já foi considerado uma área em expansão em relação à região tradicional do Nordeste. Assim, esse artigo considera que o Centro-Oeste é atualmente a região não tradicional na cultura da cana-de-açúcar.

9. Pitelli (2008) utilizou a mesma metodologia empregada nessa tese para determinar o mercado relevante para bovinos, já que "os produtos seriam agrupados em um mesmo mercado quando seus preços 'movem-se juntos'" (p. 15-16). 


\section{Referencial teórico}

$\mathrm{Na}$ análise de preços, um conceito importante diz respeito à arbitragem, que dá base para a definição da Lei do Preço Único (LPU). Como termo relacionado cita-se integração espacial de mercado (FACKLER e GOODWIN, 2001).

A LPU estabelece que, em mercados em concorrência, mas isentos de barreiras comerciais e custos de transporte, bens idênticos devem ser vendidos ao mesmo preço quando expressos na mesma moeda (KRUGMAN e OBSTFELD, 2005). Barret (2001) cita que ocorrendo o comércio e oportunidades de arbitragem, os preços são equalizados até o custo do comércio. Torna-se necessário, portanto, explicar o conceito de arbitragem.

Quando o preço do bem homogêneo apresenta diferença em mercados distintos, mas comunicantes, ocorre fluxo de bens do mercado cujo preço é inferior para o mercado que apresenta o preço maior. Esse processo de transferência de bens ocorre devido às operações de arbitragem, definida por Pindyck e Rubinfeld (2004) como "a prática de comprar a um preço mais baixo em uma localidade para vender a um preço maior em outra" (p. 8). Goodwin e Piggott (1999) descrevem que o mecanismo primário que garante a integração espacial é a arbitragem e o comércio.

Para Fackler e Goodwin (2001), as ações de arbitradores vão garantir que os preços de um bem homogêneo em dois locais distintos sejam diferentes por, no máximo, o valor do custo de mover o bem da região com menor preço para a região com o preço mais alto. Pode-se expressar esse conceito por:

$$
p_{\mathrm{j}}-p_{\mathrm{i}} \leq r_{\mathrm{ij}}
$$

em que $p_{\mathrm{j}}$ é o preço do bem na região ' $j$ ', $p_{\mathrm{i}}$ é o preço do bem na região ' $i$ ', e $r_{\mathrm{ij}}$ é o custo de transação de mover o bem da região ' $i$ ' para a região ' $j$ '.

Existe uma ampla discussão a respeito da diferença entre os conceitos LPU e mercados perfeitamente integrados. Rapsomanikis, Hallam e Conforti (2003) definem integração de mercados como a satisfação da LPU. Para Fackler e
Goodwin (2001), o conceito de integração de mercado é menos forte do que o conceito da LPU.

O uso inicial do termo integração é definido como o grau de co-movimento dos preços em locais diferentes, mensurado pela correlação entre eles. Segundo Fackler e Goodwin (2001), diante da ausência de uma definição completamente satisfatória na literatura, alguns autores propõem que o termo integração de mercado é melhor utilizado quando tomado como uma medida que trata da intensidade em que os choques de oferta e demanda em uma região são transmitidos para outras regiões. Os autores ilustram o conceito de integração espacial de mercado através de um choque hipotético, $\varepsilon_{\mathrm{A}}$, que altera o excesso de demanda por um bem na região $\mathrm{A}$, mas não na região $B$. A taxa de transmissão de preço (da região A para a região B) associada ao choque é:

$$
R_{A B}=\frac{\partial_{P B} / \partial \varepsilon_{A}}{\partial_{P A} / \partial \varepsilon_{A}}
$$

em que $\partial_{\mathrm{PB}} / \partial \varepsilon_{\mathrm{A}}$ é a variação infinitesimal do choque econômico que modifica o preço do bem na região $\mathrm{B}$ (decorrente do choque em $\mathrm{A}$ ), e $\partial_{\mathrm{PA}} / \partial \varepsilon_{\mathrm{A}}$ é a variação infinitesimal do choque econômico que modifica o preço do bem na região A. Se a relação de transmissão de preço, $R_{\mathrm{AB}}$, for 1 , há perfeita integração de mercado. Diante da possibilidade de a razão não ser simétrica $\left(R_{\mathrm{AB}} \neq R_{\mathrm{BA}}\right)$ é possível que uma região receba mais influência de outra do que o inverso.

Ao analisar a dinâmica de ajustes de preços, estudos empíricos têm abordado noções de integração de mercado mais fracas e menos restritivas, as quais reconhecem que as diferenças de preços de curto prazo podem existir. Há também testes realizados para a falta de integração: dois mercados para os quais não há transmissão de choques são não integrados ou são separados (FACKLER e GOODWIN, 2001).

Meyer (2004) cita que o termo integração de mercado, definido como o grau de transmissão de preços entre mercados espacialmente separados, tem sido usado por economistas como uma proxy para a eficiência do mercado. Mas Barret (2001) critica essa proposta. Para o autor, a 
eficiência relaciona-se à noção de preço de equilíbrio, enquanto que a integração considera os indicadores do fluxo de comercialização.

No presente estudo consideram-se mercados integrados quando há relações de longo prazo em seus preços, medidos pela existência de cointegração. Isso significa que os preços dos diferentes mercados analisados têm seus caminhos temporais ligados, embora possa haver alguns movimentos não sincronizados no curto prazo. Nesse sentido, considera-se que se está tratando de mercados integrados ou de uma LPU "fraca". Segundo Hamilton (1994), a LPU é válida se existir relações de longo prazo entre as variáveis.

\subsection{Revisão de literatura}

Os estudos relacionados à integração de mercados podem ser feitos considerando países ou regiões/estados dentro de um país. Os estudos de integração de mercados entre preços de commodities agrícolas e entre regiões brasileiras, que utilizam cointegração, foram realizados predominantemente após o ano 2000.

Em relação ao setor sucroenergético, podem-se destacar três tipos de trabalhos: aqueles que analisam a relação dos preços do açúcar no mercado doméstico com os preços internacionais, aqueles que relacionam os preços de etanol aos de gasolina ou outros produtos do setor e aqueles que tratam da integração de mercado entre regiões brasileiras.

Borges (2010) analisou a integração do mercado de açúcar nacional, representado pelos cinco maiores produtores (São Paulo, Minas Gerais, Paraná, Alagoas e Pernambuco) e destes com o mercado internacional, representado pelos preços da Bolsa de Commodities de Nova York (NYBOT). O período considerado foi de março de 2003 a setembro de 2010 e a metodologia utilizada consistiu em análise de perfil de persistência e testes sobre parâmetros. $\mathrm{O}$ autor concluiu em sua pesquisa que as praças nacionais são integradas e que estas se integram ao mercado internacional, sendo São Paulo o estado que apresentou as respostas mais rápidas aos choques advindos do mercado externo. São Paulo também foi o estado que, em relação ao grau de integração, teve os ajustes mais rápidos partindo-se de choque em mercados regionais. A pesquisa também demonstrou que, quando analisado o tempo de ajustamento aos choques, a região Norte-Nordeste apresenta um comportamento muito menos dinâmico que o da região Centro-Sul.

Serigati, Azevedo e Margarido (2012) analisaram, através do procedimento de Johansen, se o preço do etanol nos EUA e no Brasil são cointegrados, ou seja, buscaram responder se existe um mercado internacional bem desenvolvido, já que se trata dos maiores produtores de etanol. Por possuir uma relação direta, consideraram também o preço do petróleo bruto no mercado internacional. Os dados analisados foram do período de novembro de 2002 a agosto de 2011 , sendo o preço do mercado brasileiro representado pelo do estado de São Paulo e o preço dos EUA, pelo de Omaha. No caso do petróleo bruto, o preço foi o divulgado pelo FMI. O principal resultado da pesquisa foi que o mercado brasileiro e o norte-americano não são cointegrados.

Em relação aos estudos de cointegração com objetivo de avaliar a relação do preço do etanol com o da gasolina ou com os de outros produtos do setor, Gamarra e Waquil (2009) analisaram a existência de integração entre os mercados de gasolina e etanol (integração de mercados por substituição) a partir do lançamento dos carros flex. Os autores utilizaram a metodologia de causalidade de Granger e dados dos preços médios mensais para o consumidor no estado de São Paulo, de março de 2003 até julho de 2008. Os resultados mostraram que os dois mercados são cointegrados e que variações no preço da gasolina causam (no sentido de Granger) variações no preço do etanol.

Block, Coronel e Veloso (2012) analisaram o processo de transmissão de preço no setor sucroenergético, buscando explicar as influências de cada produto na formação do seu e dos demais preços. Foram utilizados no estudo os preços de cana-de-açúcar, do etanol hidratado e do açúcar no estado de São Paulo, referentes ao período 
de 1999 a 2010. A metodologia usada foi a cointegração de Engle-Granger. Os resultados mostraram que existe relação de longo prazo entre os preços dos produtos analisados e que os preços do açúcar e da cana-de-açúcar são influenciados pelo preço do etanol hidratado, mas este não é influenciado pelo preço dos demais produtos.

Alves e Lima (2010) analisaram, através do procedimento de Johansen, a transmissão de preços entre os mercados de açúcar espacialmente separados no Brasil, considerando os preços dos estados de Alagoas, Pernambuco, São Paulo, Paraná e Minas Gerais, no período de maio de 2003 a dezembro de 2008. Os principais resultados foram que o mercado central para o açúcar é Ribeirão Preto (SP) e que os mercados de açúcar são cointegrados, quando analisados aos pares. No entanto, quando impostas as restrições sobre os parâmetros, não foi encontrada evidência de integração perfeita entre os pares de mercados.

Alves e Lima (2011), utilizando o procedimento de Joahnsen, analisaram a integração dos mercados de etanol anidro e hidratado dos estados de Alagoas, Pernambuco, São Paulo e Paraná, no período de maio de 2003 a dezembro de 2008. Os resultados apontaram Ribeirão Preto (SP) como o mercado central para o etanol anidro e hidratado. Apontaram ainda que os mercados de etanol anidro e hidratado são cointegrados e que choques de preço do etanol anidro em Alagoas e Maringá/PR não são transmitidos para Ribeirão Preto (SP). Os autores observaram também que o preço vigente no mercado de hidratado de Alagoas sofre influência do preço de Ribeirão Preto, mas o inverso não ocorre. De maneira semelhante ao trabalho anterior, a restrição aos parâmetros não evidenciou a integração perfeita entre os pares de mercados analisados.

Guimarães (2011) analisou como as variações dos preços pagos ao produtor em São Paulo são transmitidas aos consumidores de outras regiões. O autor utilizou a média mensal dos preços do etanol (de janeiro de 2007 a dezembro de 2010) de 16 localidades do Brasil, compreendendo as regiões Sul, Sudeste, Centro-Oeste, e os estados do Amazonas, Pernambuco, Bahia e Maranhão. Os procedimentos metodológicos utilizados foram: causalidade de Granger; teste de cointegração de Johansen; a decomposição da variância dos erros de previsão e função impulso resposta da metodologia de Autorregressão Vetorial (VAR). Dentre os resultados, destaca-se a ausência de causalidade entre os preços de etanol ao consumidor no Nordeste com os preços ao produtor no estado de São Paulo.

Em suma, considera-se que as principais semelhanças desses estudos citados com o presente referem-se aos preços e ao objetivo. Entretanto, as diferenças estão na metodologia empregada e nos dados (período e localidades diferentes).

\section{Metodologia e dados}

O objetivo desta pesquisa é verificar as relações de longo prazo entre os preços do etanol hidratado dos principais estados produtores brasileiros. Para a obtenção dos objetivos propostos nesta pesquisa, foram realizados três procedimentos econométricos: i) teste de estacionariedade das séries temporais dos preços do etanol; ii) testes de cointegração entre as séries temporais para determinar as relações de longo prazo existentes; iii) testes de hipótese sobre os parâmetros da relação de cointegração para identificar a participação de cada mercado nas relações de longo prazo, a sensibilidade de resposta desses mercados a desequilíbrios de curto prazo e se esses mercados podem ser considerados perfeitamente integrados. Esse procedimento é semelhante ao utilizado por Chiodi (2006) para analisar cointegração no mercado brasileiro de milho. Cada uma dessas etapas será detalhada a seguir.

\subsection{Estacionariedade}

Morettin e Toloi (2004) citam que a maioria das séries tem alguma forma de não estacionariedade, devendo, antes de utilizá-las em modelos econométricos, transformá-las em séries estacionárias. 
O procedimento utilizado para a transformação de séries cuja não estacionariedade em relação à média seja devida a componente estocástico (não determinista) é tomar diferenças sucessivas (no caso de uma diferença, tem-se $\Delta x_{\mathrm{t}}=x_{\mathrm{t}}-x_{\mathrm{t}-1}$ ) até se obter uma série estacionária, ou seja, integrada de ordem zero, $\mathrm{I}(0)$. A ordem, $d$, de integração é referente ao número de vezes que a série foi diferenciada para se tornar estacionária, ou seja, após $d$ diferenças a série é estacionária de ordem $d, \mathrm{I}(\mathrm{d})$. Testes de raiz unitária são empregados para identificar a ordem de integração de uma variável.

\subsubsection{Testes de raiz unitária}

Entre os testes de raiz unitária citam-se os de Dickey-Fuller - DF, de Dickey-Fuller Aumentado - ADF, o de Dickey e Pantula - DP para duas raízes, o DF GLS, entre outros ${ }^{10}$.

Dentre os testes de raiz unitária, o mais usual é o teste de Dickey-Fuller Aumentado - ADF. O teste desenvolvido por Elliott, Rothenberg e Stock (1996) consiste em um teste do tipo ADF modificado, e recebe a denominação de Teste Dickey-Fuller - Generalized Least Squares ou simplesmente teste DF-GLS.

Bueno (2008) cita que o teste ADF tem seu poder reduzido consideravelmente na presença de termos deterministas, sendo que o DF-GLS é um teste que filtra a presença de constante e/ou tendência, geralmente presentes em séries temporais, aumentando o poder do teste.

No estudo foi utilizado o referido teste, considerando Critério Modificado de Akaike - MAIC proposto por Ng e Perron (2001) para definir o número de defasagens.

\subsection{Testes de cointegração - métodos de Engle e Granger e Johansen}

Verificada a presença de raiz unitária nas séries temporais usadas no modelo, a análise de

10. Para mais detalhes, ver Bueno (2008, p. 97-123). cointegração torna-se necessária. Segundo Engle e Granger (1987, p. 253)

"The components of the vector $X_{\mathrm{t}}$ are said to be co-integrated of order $d, b$, denoted $x_{\mathrm{t}} \sim$ $\mathrm{CI}(\mathrm{d}, \mathrm{b})$, if: (i) all components of $X_{\mathrm{t}}$ are I(d); (ii) there exists a vector $\alpha(\neq 0)$ so that $z_{\mathrm{t}}=\alpha^{\prime} x_{\mathrm{t}}$ $\sim \mathrm{I}(\mathrm{d}, \mathrm{b}), \mathrm{b}>0$. The vector $\alpha$ is called the co-integrating vector".

O teste de Johansen $(1988)^{11}$ foi utilizado neste estudo para a análise de cointegração uma vez que ele possibilita estimar e testar a presença de múltiplos vetores de cointegração e não exige a pressuposição de exogeneidade dos regressores.

Harris (1995) cita que entre as duas estatísticas utilizadas por Johansen nos testes de cointegração, $\lambda_{\max }$ e traço, a última é mais robusta.

O número de defasagens a ser incluído no modelo é determinado pela forma multivariada dos critérios de informação Schwarz - SC.

\subsection{Teste de hipóteses sobre as relações de cointegração ${ }^{12}$}

Após determinar o posto da matriz $\Pi$ pela análise no procedimento de Johansen, a matriz $\Pi$ é decomposta na matriz $\beta$, a qual representa os coeficientes das relações de longo prazo, e na matriz $\alpha$, que representa a velocidade de ajustamento aos desequilíbrios de longo prazo. Sobre a matriz $\beta$ de longo prazo pode-se aplicar restrições, motivadas por argumentos econômicos, com a intenção de verificar se esses vetores revelam relações como $\beta_{1 \mathrm{j}}=-\beta_{2 \mathrm{j}}$, ou seja, se esses mercados são perfeitamente integrados. Pode-se testar, também, se $\beta_{\mathrm{ij}}$ é nulo.

No caso da existência de cointegração, a seguinte equação é utilizada:

$$
\mathrm{H}_{\beta}: \beta=\left(\mathrm{H}_{1} \varphi_{1}, \mathrm{H}_{2} \varphi_{2}, \ldots, \mathrm{H}_{\mathrm{r}} \varphi_{\mathrm{r}}\right)
$$

em que a matriz $H_{1}, \ldots, H_{\mathrm{r}}$, de ordem $n \times s_{\mathrm{i}}$, expressa a hipótese econômica a ser testada em cada uma

11. O teste de Johansen (1988) está baseado em Enders (2010), Bueno (2008) e nos originais.

12. Tópico desenvolvido com base nos originais e Harris (1995). 
das $r$ relações de cointegração, e $\varphi_{\mathrm{i}}$ é um vetor $\left(s_{\mathrm{i}} \times 1\right)$ dos parâmetros a serem estimados na i-ésima relação de cointegração. Sendo $n$ o número de variáveis consideradas no modelo, $s_{\mathrm{i}}$ representa os parâmetros não restritos em $\beta_{\mathrm{i}}$, e $k_{\mathrm{i}} \mathrm{o}$ número de restrições impostas na matriz $H_{\mathrm{i}}$, tal que $k_{\mathrm{i}}+s_{\mathrm{i}}=n$.

Johansen e Juselius (1992, p. 226) sugerem três hipóteses a serem testadas sobre o vetor $\beta$ :

a) na primeira hipótese impõe-se as mesmas restrições sobre todos os vetores de cointegração, sendo especificada da seguinte forma: $H_{2}: \beta=H \varphi$, em que $H$ é uma matriz de ordem $(n \times r)$ e $\varphi$ é de ordem $(s \times r), r \leq s \leq n$. Essa hipótese é utilizada para testar se uma determinada estrutura se mantém em todas as relações de cointegração. De outro modo: testa-se $\beta_{\mathrm{ij}}=\beta_{2 \mathrm{j}}$ em todos os vetores para identificar a existência de perfeita integração. Esse teste é baseado na distribuição $\chi^{2}$ com $(r \times k)$ graus de liberdade;

b) na segunda hipótese assume-se que $r_{1}$ das $r$ relações de cointegração tenham restrições e as demais não. Essa hipótese, menos restritiva que a anterior, pode ser especificada como $\mathrm{H}_{3}: \beta=\left(\mathrm{H}_{1} \varphi_{1}, \mathrm{H}_{2} \varphi_{2}\right)$ com $H_{1}$ e $\mathrm{H}_{2}$ representando dois grupos, sendo o primeiro, com dimensão $(n \times s)$, dos parâmetros com restrições e o segundo, não restrito, é uma matriz identidade $I_{\mathrm{n}}$ com dimensão $(n \times n)$. Consequentemente, a matriz $\varphi_{1}$, de ordem $\left(s \times r_{1}\right)$, refere-se aos parâmetros a serem estimados no grupo em que são impostas restrições, e $\varphi_{2}$, de ordem $\left(n \times r_{2}\right)$, contemplam os parâmetros do segundo grupo. No caso do presente estudo, testa-se se a relação de perfeita integração prevalece em pelo menos um vetor de cointegração. Esse teste estatístico tem distribuição $\chi^{2} \operatorname{com} r_{1}(n-r)$ graus de liberdade;

c) a terceira hipótese, menos restritiva ainda, apresenta uma diferença na matriz $H_{1}$ em relação à hipótese anterior. Aqui, não se exige que o conceito de perfeita integração prevaleça, admitindo-se uma relação estável (estacionária) entre duas variáveis. Esse teste possui distribuição $\chi^{2}$ $\left(n-s-r_{2}\right) r_{1}$ graus de liberdade.

\subsection{Teste de hipóteses sobre o parâmetro $\alpha-$ teste para exogeneidade fraca}

Verificada a existência de $r$ vetores de cointegração, a matriz $\Pi$ é decomposta na matriz $\beta$, a qual representa os coeficientes das relações de longo prazo, e na matriz $\alpha$, que representa a velocidade de ajustamento aos desequilíbrios de longo prazo. Bueno (2008) explica que, economicamente, cointegração significa que existe uma relação de longo prazo, a qual é perturbada por choques de curto prazo, mas que se dissipam ao longo do tempo, voltando ao equilíbrio de longo prazo. O parâmetro $\alpha$ está relacionado ao tempo necessário para a dissipação do choque, ou seja, pode ser interpretado como a velocidade de ajustamento quando a trajetória de longo prazo é alterada.

Enders (2010) explica que, em um sistema cointegrado, se o parâmetro $\alpha$ é zero, a variável em questão é fracamente exógena, de modo que essa variável não responde aos desvios da relação de equilíbrio de longo prazo.

Suponha, por exemplo ${ }^{13}$, que se deseja testar a imposição de $m$ restrições lineares sobre $\alpha$ da seguinte forma:

$$
\alpha=\mathrm{A} \phi \quad \text { ou } \quad \mathrm{B}^{\prime} \alpha=0
$$

em que $A$ é uma matriz $(n \times m)$, $\phi$ uma matriz $(m \times r)$ e $B$ é de ordem $(n \times(n-m))$ e ortogonal a $A$, ou seja, $B^{\prime} A=0$. O teste corresponde a:

$$
H_{0}: \alpha_{\mathrm{i}}=0 \quad i=1,2, k, r
$$

Da mesma forma que os testes sobre o vetor $\beta$, os teste de hipótese sobre o vetor $\alpha$, para a obtenção do nível de significância para a rejeição da hipótese nula, seguem uma distribuição $\chi^{2}$ com $(r \times(n-m))$ graus de liberdade, sendo que $(n-m)$ refere-se ao número de linhas restritas sobre $\alpha$.

13. Baseado em Nakane (1994). 


\subsection{Dados}

Os dados utilizados são os preços mensais do etanol hidratado do segmento produtor nos estados de São Paulo, Minas Gerais, Paraná, Mato Grosso, Goiás, Mato Grosso do Sul, Alagoas e Pernambuco, coletados pelo Centro de Estudos Avançados em Economia Aplicada (Cepea). A série histórica utilizada no estudo abrange o período de abril de 2008 a março de 2013. Optou-se por utilizar no estudo dados a partir de 2008, pois a partir desse período é que alguns estados da região Centro-Sul passaram a ter maior representatividade no mercado brasileiro de etanol. Os preços foram deflacionados utilizando o Índice Geral de Preços (IGP-DI) divulgado pela Fundação Getúlio Vargas (FGV).

Todos os procedimentos estatísticos foram realizados com o software Regression Analysis of Time Series (RATS).

Ressalta-se que na revisão da metodologia não se encontrou qualquer trabalho sobre integração espacial (utilizando método multiequacional) para o mercado de etanol. Esse fato era esperado uma vez que só recentemente são disponibilizadas séries de preços desse combustível para os principais estados produtores, as quais devem ser suficientemente longas para que se possa captar um padrão de associação entre elas.

\section{Resultados e discussões}

O teste de raiz unitária utilizado, cujos resultados são apresentados na Tabela 1, foi o desenvolvido por Elliott, Rothenberg e Stock (1996), conhecido como DF-GLS. A segunda coluna da tabela apresenta o número de defasagens, a qual foi determinada de acordo com o critério de informação de Akaike modificado (MAIC). Na presença de dois valores nessa coluna, o primeiro refere-se ao modelo 1 , no qual se considerou constante e tendência, e o segundo ao modelo com constante apenas, denominado de modelo 2 .

Verifica-se que todas as séries são I(1), ou seja, não estacionárias, uma vez que a hipótese de raiz unitária não foi rejeitada. Esse resultado é obtido nas duas versões do modelo, o que os torna robustos.

Constatado que as séries são integradas de ordem I(1), foi realizado o teste de cointegração de Johansen (1988) para analisar a existência de relações de longo prazo entre as variáveis. A inspeção gráfica das séries e dos resíduos dos modelos alternativos ajustados permitiu a definição do(s) termo(s) determinista(s) a serem incluídos no modelo: uma constante no vetor de cointegração. Em relação ao número de lags para os testes de cointegração, o Critério de Informação de Schwarz multiequacional (Schwarz Criterion - SC)

Tabela 1. Resultados dos testes de raiz unitária de Elliott-Rothenberg-Stock (DF-GLS) - estados selecionados

\begin{tabular}{lccc}
\hline \multirow{2}{*}{ Variáveis } & \multirow{2}{*}{ Defasagens/Lag $(\mathbf{p})$} & Modelo 1 & Modelo 2 \\
\cline { 3 - 4 } & & Estatística DF-GLS & Estatística DF-GLS \\
\hline Goiás & $1 ; 10$ & $-3,348$ & $-1,141$ \\
Mato Grosso & 7 & $-1,576$ & $-1,643$ \\
Mato Grosso do Sul & $2 ; 10$ & $-2,942$ & $-0,681$ \\
Minas Gerais & 1 & $-2,818$ & $-2,149$ \\
Paraná & 1 & $-2,605$ & $-1,947$ \\
São Paulo & 1 & $-2,837$ & $-2,026$ \\
Alagoas & $2 ; 10$ & $-2,275$ & $-0,586$ \\
Pernambuco & 4 & $-2,113$ & $-1,308$ \\
\hline
\end{tabular}

Nota: Modelo 1: na versão com constante e tendência (valores críticos em Elliott, Rothenberg e Stock $(1996)(5 \%=-2,93,1 \%=-3,46)$ ); Modelo 2: na versão apenas com constante (valores críticos em Dickey e Fuller $(1979 ; 1981)(5 \%=-1,95$ e $1 \%=-2,58))$.

Fonte: Elaborado pelos autores com dados da pesquisa. 
foi utilizado e indicou que o modelo deveria ser ajustado como uma defasagem.

A Tabela 2 apresenta os resultados relativos ao teste de cointegração de Johansen. Desde que 6,216 é menor do que o valor crítico de 5\% de 9,142, não é possível rejeitar a hipótese nula a este nível de significância. Portanto, os resultados dos testes de cointegração apontam para existência de sete vetores.

Sabe-se que a existência dos vetores de cointegração não é condição necessária e suficiente para se determinar a participação de todas as séries no equilíbrio de longo prazo. Para tal, há necessidade de se aplicar testes de hipótese sobre os parâmetros.

Inicialmente testou-se a significância dos coeficientes $\beta$, a fim de determinar quais das variáveis participavam efetivamente do equilíbrio de longo prazo. A seguinte hipótese é considerada:

$$
\mathrm{H}_{0}: \beta \mathbf{i}=0
$$

Os resultados são apresentados na Tabela 3 e indicam a rejeição da hipótese nula de $\beta_{\mathrm{i}}-0$ para todas as séries de preços, ou seja, todos os parâmetros estimados participam das sete relações de cointegração, exercendo influência nos movimentos de preços do mercado.

Constatada a existência de cointegração entre as variáveis, analisou-se a hipótese de perfeita integração entre os pares de mercados sem restringir a zero os parâmetros associados aos preços dos demais estados, conforme apresentado na metodologia. Os resultados de perfeita integração entre os estados do Brasil, sem restringir a zero os demais parâmetros, apresentados na Tabela 1A (Anexo), mostram que em todos os casos se rejeita a hipótese nula. Ressalta-se que a hipótese nula é imposta em

Tabela 2. Resultados do teste de cointegração de Johansen

\begin{tabular}{cccc}
\hline Hipótese Nula & Hipótese Alternativa & Estatística Traço & Valores Críticos (5\%) \\
\hline $\mathrm{r} \leq 7$ & $\mathrm{r}>7$ & 6,216 & 9,142 \\
$\mathrm{r} \leq 6$ & $\mathrm{r}>6$ & 20,831 & 20,164 \\
$\mathrm{r} \leq 5$ & $\mathrm{r}>5$ & 38,058 & 35,070 \\
$\mathrm{r} \leq 4$ & $\mathrm{r}>4$ & 59,969 & 53,945 \\
$\mathrm{r} \leq 3$ & $\mathrm{r}>3$ & 104,386 & 76,813 \\
$\mathrm{r} \leq 2$ & $\mathrm{r}>2$ & 158,495 & 103,679 \\
$\mathrm{r} \leq 1$ & $\mathrm{r}>1$ & 228,606 & 134,543 \\
$\mathrm{r}=0$ & $\mathrm{r}>0$ & 336,485 & 169,405 \\
\hline
\end{tabular}

Nota: Os valores críticos são de Osterwald-Lenun (1992).

Fonte: Elaborado pelos autores com dados da pesquisa.

Tabela 3. Teste sobre a significância dos parâmetros $\beta$ nas variáveis - estados selecionados

\begin{tabular}{cc}
\hline$H_{0}$ & Razão de Verossimilhança \\
\hline$\beta_{\mathrm{GO}}=0$ & $33.984^{* *}$ \\
$\beta_{\mathrm{MT}}=0$ & $18.424^{* *}$ \\
$\beta_{\mathrm{MS}}=0$ & $51.968^{* *}$ \\
$\beta_{\mathrm{MG}}=0$ & $53.543^{* *}$ \\
$\beta_{\mathrm{PR}}=0$ & $52.715^{* *}$ \\
$\beta_{\mathrm{SP}}=0$ & $91.970^{* *}$ \\
$\beta_{\mathrm{AL}}=0$ & $33.748^{* *}$ \\
$\beta_{\mathrm{PE}}=0$ & $36.382^{* *}$ \\
$\beta_{\mathrm{Constante}}=0$ & $23.257^{* *}$ \\
\hline
\end{tabular}

Nota: Dois asteriscos indicam rejeição a $10 \%$ de significância - Valor Crítico $\chi^{2}(10 \%) 12,02$.

Fonte: Elaborado pelos autores com dados da pesquisa. 
todos os vetores de cointegração, sendo, portanto, bastante restritiva.

Na Tabela 2A (Anexo) apresentam-se os resultados dos testes de integração entre os pares de mercados considerando que os demais preços não interferem na existência de integração perfeita entre os mercados de interesse. Nesse caso, restringe-se a zero os parâmetros dos preços que não estão sendo testados. Os resultados mostram que os estados de São Paulo, Paraná, Minas Gerais e Goiás são perfeitamente integrados entre si. Outra relação de perfeita integração existente ocorre entre os estados da região Norte-Nordeste: Pernambuco e Alagoas. Verificou-se que Alagoas apresenta perfeita integração com Mato Grosso do Sul. Em relação a essa integração perfeita não esperada entre Alagoas e Mato Grosso do Sul, considera-se que pode (m) ter havido período(s) das séries de preços cujas variações foram similares, mesmo sem haver fundamentos econômicos fortes para isso.

Nos casos em que não se constatou, com os procedimentos anteriores, a existência de perfeita integração, com ou sem interferência dos demais preços no par que está sendo testado, formulou-se uma hipótese mais flexível, verificando se há uma relação estacionária entre as séries em um dos vetores de cointegração. A Tabela 4 apresenta esses resultados, verificando que a integração é rejeitada apenas nos casos de Mato Grosso do Sul com todos os demais estados, e também entre Mato Grosso e São Paulo. Nesses casos, constatou-se que não há relações estacionárias entre os preços do etanol nesses estados. Assim, os preços em Mato Grosso do Sul parecem ter um comportamento mais independente do que os preços dos demais estados brasileiros.

Analisada a relação de integração entre os pares de mercados, a última hipótese a ser testada é sobre os parâmetros $\alpha$, correspondentes aos desvios de curto prazo. O teste de exogeneidade fraca permite determinar de que forma cada variável reage aos desequilíbrios de curto prazo, retornando ao equilíbrio de longo prazo. Para tal, testa-se a seguinte hipótese:

$$
H_{0}: \alpha_{\mathrm{i}}=0
$$

Tabela 4. Teste sobre a relação de integração entre os pares de mercados

\begin{tabular}{cc}
\hline$H_{0}$ & Razão de Verossimilhança \\
\hline$\beta_{\mathrm{GO}}=\beta_{\mathrm{MT}}$ & 1.280 \\
$\beta_{\mathrm{GO}}=\beta_{\mathrm{MS}}$ & $4.846^{* *}$ \\
$\beta_{\mathrm{GO}}=\beta_{\mathrm{AL}}$ & 0.310 \\
$\beta_{\mathrm{GO}}=\beta_{\mathrm{PE}}$ & 0.469 \\
$\beta_{\mathrm{MT}}=\beta_{\mathrm{MS}}$ & $3.583^{* *}$ \\
$\beta_{\mathrm{MT}}=\beta_{\mathrm{MG}}$ & 2.159 \\
$\beta_{\mathrm{MT}}=\beta_{\mathrm{PR}}$ & 2.132 \\
$\beta_{\mathrm{MT}}=\beta_{\mathrm{SP}}$ & $2.842^{* *}$ \\
$\beta_{\mathrm{MT}}=\beta_{\mathrm{AL}}$ & 0.026 \\
$\beta_{\mathrm{MT}}=\beta_{\mathrm{PE}}$ & 0.000 \\
$\beta_{\mathrm{MS}}=\beta_{\mathrm{MG}}$ & $6.661^{* *}$ \\
$\beta_{\mathrm{MS}}=\beta_{\mathrm{PR}}$ & $7.007^{* *}$ \\
$\beta_{\mathrm{MS}}=\beta_{\mathrm{SP}}$ & $5.541^{* *}$ \\
$\beta_{\mathrm{MS}}=\beta_{\mathrm{PE}}$ & $2.921^{* *}$ \\
$\beta_{\mathrm{MG}}=\beta_{\mathrm{AL}}$ & 0.896 \\
$\beta_{\mathrm{MG}}=\beta_{\mathrm{PE}}$ & 1.186 \\
$\beta_{\mathrm{PR}}=\beta_{\mathrm{AL}}$ & 1.425 \\
$\beta_{\mathrm{PR}}=\beta_{\mathrm{PE}}$ & 1.730 \\
$\beta_{\mathrm{SP}}=\beta_{\mathrm{AL}}$ & 1.966 \\
$\beta_{\mathrm{SP}}=\beta_{\mathrm{PE}}$ & 2.278 \\
\hline
\end{tabular}

Nota: Dois asteriscos indicam rejeição da hipótese de perfeita integração a um nível de significância de $10 \%$ - Valor Crítico $\chi^{2}(10 \%)$ 2,71.

Fonte: Elaborado pelos autores com dados da pesquisa. 
A Tabela 5 apresenta os resultados da significância dos parâmetros $\alpha$, indicando a rejeição da hipótese nula. Assim, todos os preços dos estados analisados reagem aos desequilíbrios transitórios provenientes de choques não esperados, retomando o equilíbrio de longo prazo.

Para melhor visualização dos resultados, foram elaborados organogramas. A Figura 1 apresenta as relações de perfeita integração para os pares de mercado analisados. Na parte inferior são apresentados resultados de perfeita integra- ção entre os estados da região Norte-Nordeste analisados: Pernambuco e Alagoas.

Foram observadas relações adicionais quando foram consideradas condições menos restritivas que integração perfeita, com ou sem imposição de efeitos dos demais preços sobre os pares de mercado estudados.

As Figuras 2, 3, 4 e 5 apresentam as relações dos mercados que são perfeitamente integrados entre si (Goiás, Minas Gerais, Paraná e São Paulo) com os demais mercados.

Tabela 5. Teste sobre a significância dos parâmetros $\alpha$ para os estados, sem restrições sobre os parâmetros $\beta$

\begin{tabular}{cc|cc}
\hline$H_{0}$ & Razão de verossimilhança & $H_{0}$ & Razão de verossimilhança \\
\hline$\alpha_{\mathrm{GO}}=0$ & $23.054^{* *}$ & $\alpha_{\mathrm{PR}}=0$ & $33.159^{* *}$ \\
$\alpha_{\mathrm{MT}}=0$ & $30.543^{* *}$ & $\alpha_{\mathrm{SP}}=0$ & $20.663^{* *}$ \\
$\alpha_{\mathrm{MS}}=0$ & $12.480^{* *}$ & $\alpha_{\mathrm{AL}}=0$ & $24.816^{* *}$ \\
$\alpha_{\mathrm{MG}}=0$ & $18.398^{* *}$ & $\alpha_{\mathrm{PE}}=0$ & $15.501^{* *}$ \\
\hline
\end{tabular}

Nota: Dois asteriscos indicam rejeição a 10\% de significância - 10\% - Valor Crítico $\chi^{2}(10 \%)$ 12,02.

Fonte: Elaborado pelos autores com dados da pesquisa.

Figura 1. Relação de perfeita integração entre os preços do mercado brasileiro de etanol hidratado significativo a 10\%

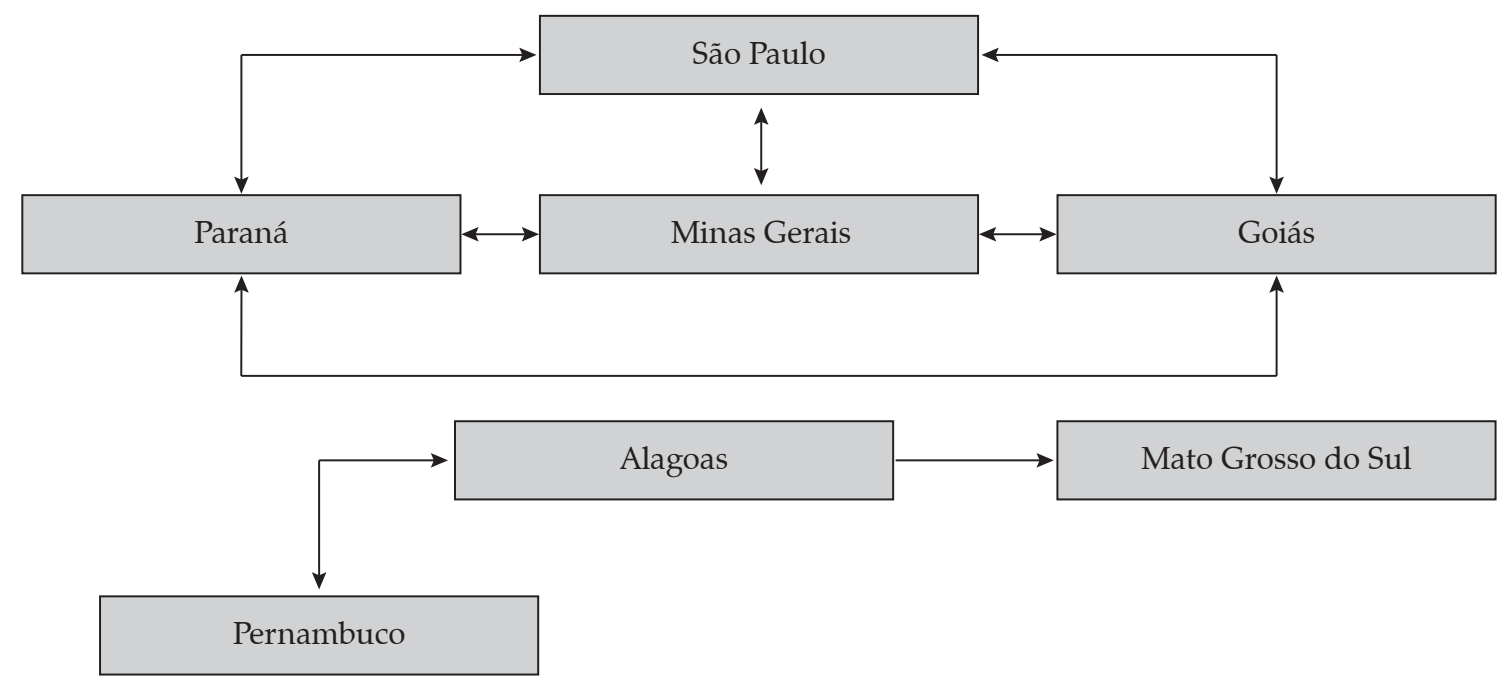

Fonte: Elaboração dos autores. 
Figura 2. Relação de integração entre os preços do etanol hidratado de Goiás e dos demais estados

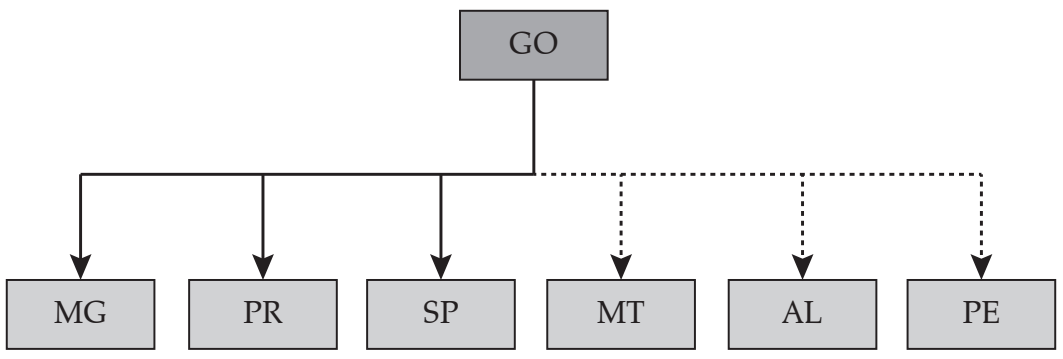

$\longleftrightarrow$ Mercados perfeitamente integrados a um nível de significância de 10\%; $\longleftrightarrow$ - - Mercados integrados a um nível de significância de $10 \%$ Fonte: Elaboração dos autores.

Figura 3. Relação de integração entre os preços do etanol hidratado de Minas Gerais e dos demais estados

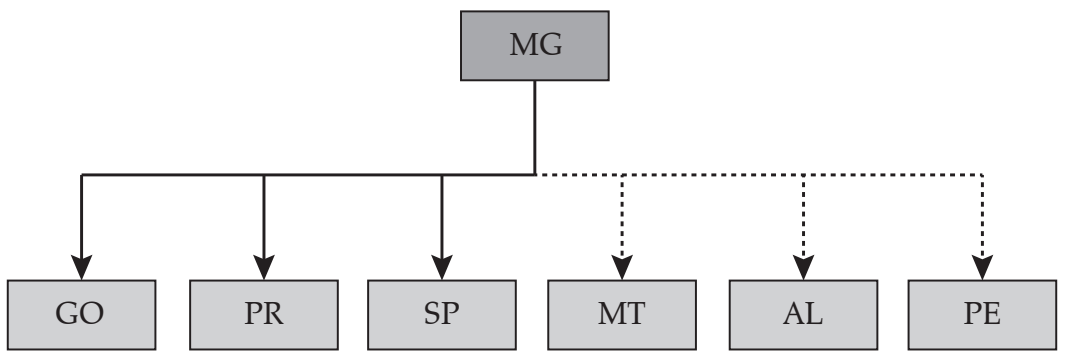

$\longleftrightarrow$ Mercados perfeitamente integrados a um nível de significância de $10 \%$; Fonte: Elaboração dos autores.

Figura 4. Relação de integração entre os preços do etanol hidratado do Paraná e dos demais estados

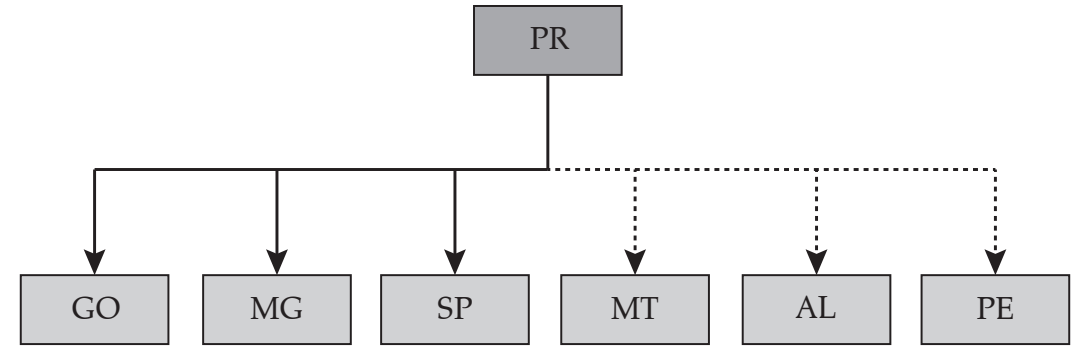

$\longleftrightarrow$ Mercados perfeitamente integrados a um nível de significância de 10\%; $\leftrightarrow--$ Mercados integrados a um nível de significância de $10 \%$ Fonte: Elaboração dos autores.

Figura 5. Relação integração entre os preços do etanol hidratado de São Paulo e dos demais estados

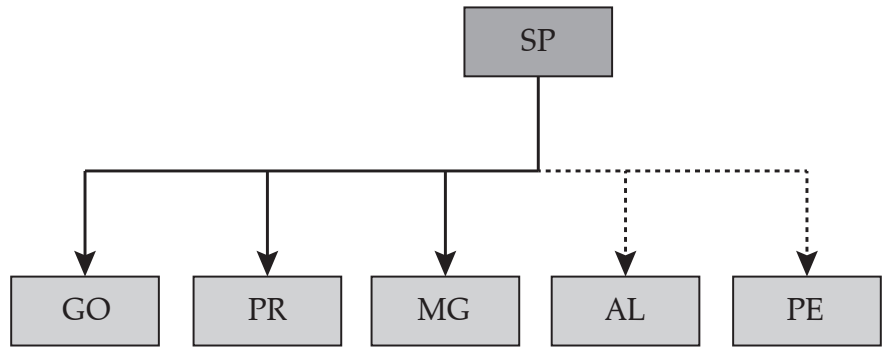

$\longleftrightarrow$ Mercados perfeitamente integrados a um nível de significância de 10\%; $\longleftrightarrow--$ Mercados integrados a um nível de significância de $10 \%$ Fonte: Fonte: Elaboração dos autores. 
Cabe ressaltar que, desses quatro estados analisados, apenas São Paulo não apresentou relação com Mato Grosso. A integração perfeita entre os mercados de São Paulo, Minas Gerais, Paraná e Goiás pode ser explicada pela localização geográfica (logística) e pelo volume de produção, sendo esses estados os maiores produtores de cana-de-açúcar do País.

A maior concentração da produção da cana-de-açúcar ocorre em São Paulo e nos estados com que ele faz divisa (com exceção da pequena fronteira com o Rio de Janeiro). Na média do período 2008 a 2012, os quatro estados (São Paulo, Paraná, Minas Gerais e Goiás) representaram 81,9\% da produção nacional de etanol hidratado, sendo que São Paulo tem um peso considerável (53,4\% na média do período). Embora São Paulo apresente, na média do período, uma grande participação, uma queda ao longo do tempo tem sido observada, de 59,8\% em 2008 para 46\% em 2012 (ANP, 2013).

É possível fazer inferências sobre questões logísticas: a localização central desse grupo de estados possibilita escoamento de combustível para a região Norte e, principalmente, para as regióes Nordeste e Sul do Brasil.

Um fator que pode estar contribuindo para a existência de integração de preços de etanol entre estes estados brasileiros é a concentração crescente no setor produtivo e de comercialização. É sabido que grupos do segmento produtor de etanol do estado de São Paulo expandiram a produção de suas empresas adquirindo outras no Centro-Oeste. De outro lado, empresas de comercialização que representavam usinas de São Paulo passaram a comercializar também produto de outros estados. Não obstante, grupos do Nordeste passaram a produzir e comercializar etanol em estados da região Centro-Sul.

Os resultados apontaram que os estados de São Paulo, Goiás, Paraná e Minas Gerais, que são perfeitamente integrados entre si, apresentam relações de preços com os estados do Nordeste e Mato Grosso, embora não se configure perfeita integração.

As relações de integração do estado de Mato Grosso estão apresentadas na Figura 6.

Observa-se que o estado de Mato Grosso é o único analisado que não apresenta relação de perfeita integração com qualquer outro estado (Figura 6), mesmo que seus preços apresentem algumas relações com preços de alguns estados do Centro-Sul e do Norte-Nordeste.

A ausência de relação forte de preços de Mato Grosso com os dos demais estados pode ser explicada pelo fato de este estado referir-se ao mercado vocacional, isto é, a negócios feitos cuja origem e destino são o próprio estado.

Além do mais, a tributação de Mato Grosso no que diz respeito ao Imposto sobre Circulação de Mercadorias e Prestação de Serviços (ICMS) é totalmente diferente da praticada em outros estados, quer da região Centro-Sul, quer da região Norte-Nordeste. Em Mato Grosso, o ICMS é cobrado sobre valor de pauta estabelecido pelo governo do estado, tomando como referência o preço de varejo.

Figura 6. Relação de integração entre os preços do etanol hidratado de Mato Grosso e dos demais estados

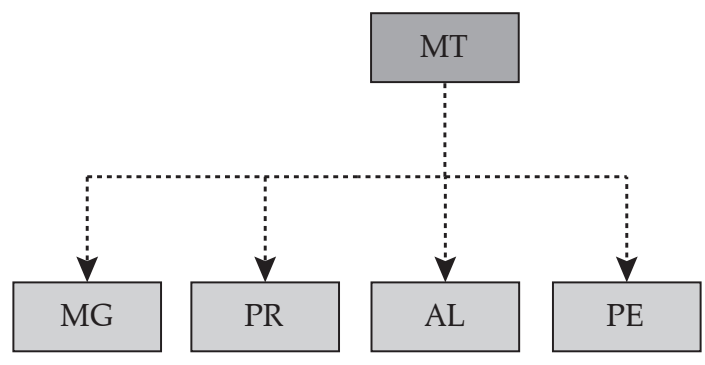

- - - Mercados integrados a um nível de significância de 10\%

Fonte: Elaboração dos autores. 
O montante associado a esse tributo não representa o que é recolhido na íntegra pela maior parte dos produtores de etanol: um incentivo do governo estadual, estabelecido através de um protocolo, isenta o recolhimento integral do ICMS devido. Além disto, a posição geográfica do estado possibilita o escoamento da produção para os da região Norte. Em termos de fluxo, além dos estados da região Norte, Mato Grosso abastece o próprio estado, sendo raras outras rotas.

Mato Grosso do Sul apresenta o menor número de relações de preços com os demais estados. O estado apresenta apenas uma relação de perfeita integração com Alagoas, resultado esse não esperado.

As Figuras 7 e 8 apresentam as relações dos estados da região Norte-Nordeste com os demais estados brasileiros.

O estado de Alagoas apresenta relação com todos os estados analisados, com exceção do
Paraná. Já Pernambuco também apresenta relação com todos os estados, exceção ao estado de Mato Grosso do Sul.

A participação dos estados de Alagoas e Pernambuco na região Nordeste, na média do período, é de $57,1 \%$ da produção de etanol hidratado. No entanto, em 2008, esses estados representaram $65,4 \%$ da produção da região, caindo para 47\% em 2012 (ANP, 2013). Em relação ao número de usinas, dados do Ministério da Agricultura, Pecuária e Abastecimento (MAPA, 2013) mostram que esses estados, em conjunto, possuem 41 usinas, representando $58 \%$ das usinas da região.

Assim, a relação de perfeita integração entre os estados de Alagoas e Pernambuco era esperada, já que se trata dos maiores produtores da região Nordeste, junto à Paraíba. No entanto, a relação perfeita entre Alagoas e Mato Grosso do Sul não era esperada, mesmo tendo sido considerada

Figura 7. Relação de integração entre os preços do etanol hidratado de Alagoas e dos demais estados

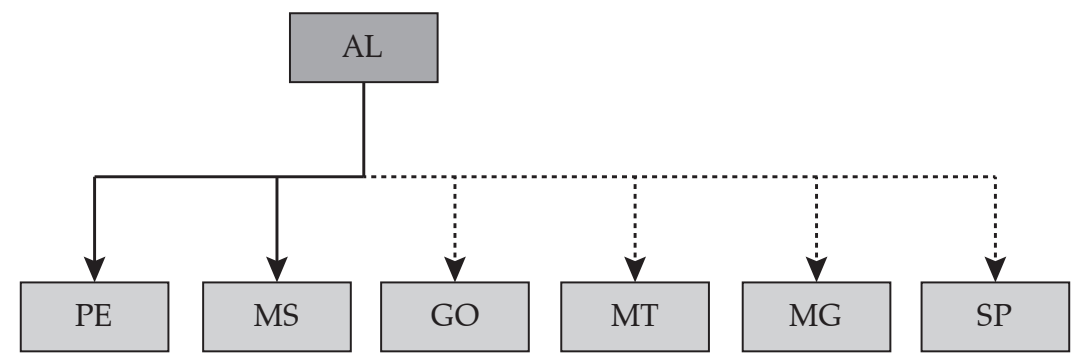

$\longleftrightarrow$ Mercados perfeitamente integrados a um nível de significância de 10\%; $\longleftrightarrow-$ - Mercados integrados a um nível de significância de $10 \%$ Fonte: Elaboração dos autores.

Figura 8. Relação de integração entre os preços do etanol hidratado de Pernambuco e dos demais estados

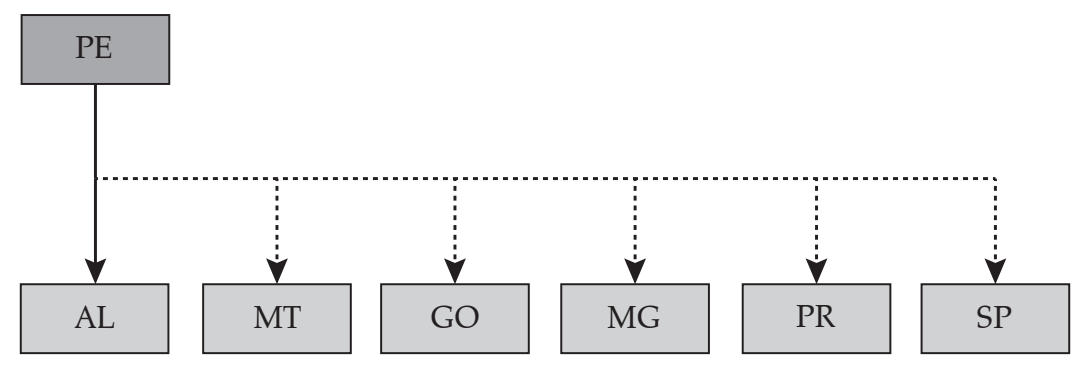

$\longleftrightarrow$ Mercados perfeitamente integrados a um nível de significância de 10\%; $\longleftrightarrow-$ - Mercados integrados a um nível de significância de $10 \%$ Fonte: Elaboração dos autores. 
fraca do ponto de vista estatístico (valor do teste muito próximo ao crítico).

A ausência de fortes relações dos preços dos estados do Centro-Sul com os do Norte-Nordeste deve-se, em grande medida, ao fato de os períodos de safra e entressafra nas regiões Norte-Nordeste e Centro-Sul serem diferentes e, também, à representatividade das duas regióes no contexto da produção brasileira de etanol. Embora existam operações de cabotagem da região Centro-Sul para a Norte-Nordeste e destinação de produto do Centro-Sul para o Norte-Nordeste por via rodoviária, elas não são tão expressivas de forma a permitir que as relações de preços sejam muito fortes.

A presença de relações, mesmo que 'fracas', entre os preços dessas duas regiões permite levantar a hipótese de que os produtores da região Nordeste precificam o etanol comercializado naquela região considerando os preços na região Centro-Sul e o diferencial de frete.

\section{Considerações finais}

Os resultados mostram que os estados de São Paulo, Paraná, Minas Gerais e Goiás são perfeitamente integrados e apresentam integração, embora não perfeita, com os estados de Mato Grosso, Alagoas e Pernambuco, com exceção de São Paulo com Mato Grosso.

A integração perfeita entre os mercados de São Paulo, Minas Gerais, Paraná e Goiás pode ser explicada não só por questões logísticas, mas também pelo fato de esses estados serem os maiores produtores de etanol do território nacional. Assim, espera-se que a arbitragem, em termos de volume, seja maior entre esses estados, o que faz com que as relações de preços entre eles sejam fortes. O fato de não serem observadas relações expressivas entre o preço de Mato Grosso do Sul com os preços dos demais estados da região Centro-Sul permite que se conclua que a questão logística (proximidade), por si só, não é suficiente para que exista integração perfeita.

Já a ausência de fortes relações dos preços dos estados do Centro-Sul com os do Norte-Nordeste deve-se ao fato de os períodos de safra e entressafra nas regiões Norte-Nordeste e Centro-Sul serem diferentes e ao fato de a representatividade da produção de etanol de cada região na produção nacional ter uma diferença expressiva. Embora existam operações de cabotagem da região Centro-Sul para a Norte-Nordeste e destinação de produto do Centro-Sul para o Norte-Nordeste por via rodoviária, elas não são tão expressivas de forma a permitir que as relações de preços sejam muito estreitas.

Os estados da região Norte-Nordeste são perfeitamente integrados. A relação de perfeita integração entre os estados de Alagoas e Pernambuco era esperada, já que se trata dos maiores produtores da região Nordeste, além de serem estados vizinhos.

Destaca-se também que Mato Grosso não apresentou relação de perfeita integração com qualquer outro estado. Um dos fatores que podem explicar a ausência de forte relação do preço de Mato Grosso com os dos demais estados do Centro-Sul é a tributação, no que diz respeito ao ICMS, a qual é diferente da praticada nos demais estados, quer da região Centro-Sul, quer da região Norte-Nordeste.

Conclui-se, assim, que relações de perfeita integração são encontradas, na maior parte das vezes, entre estados de uma mesma região (Centro-Sul e Norte-Nordeste). Constatou-se, no entanto, algumas relações de integração, ainda que não perfeitas, entre estados de regiões diferentes. Assim, a rejeição ou não da hipótese de existência de um único mercado para o etanol no Brasil depende das premissas adotadas em relação à integração perfeita ou não. Num cenário menos restritivo, em que se admite integração não perfeita, considera-se que existe um único mercado para o etanol no Brasil.

$\mathrm{O}$ fato de se ter observado que mercados são integrados permite concluir que eventuais políticas que afetem o processo de formação de preços em um estado vão também ter efeito nos preços de todos os demais estados com os quais ele esteja integrado, especialmente naqueles nos quais as relações são fortes. O esforço que representantes 
do setor produtivo de etanol estão fazendo para que a política tributária relativa ao ICMS seja uniformizada encontra respaldo neste estudo.

Observando-se relações de preços de longo prazo significativas entre estados de uma mesma região e, em alguns casos, de regiões diferentes, sugere-se, para completar essa análise, que se busque estimar elasticidades de transmissão de preços de curto e longo prazo, as quais poderão fundamentar análises prospectivas.

De um caráter mais descritivo e qualitativo, estudos futuros poderão buscar responder por que o etanol nem sempre é competitivo frente à gasolina em alguns estados do Centro-Oeste, que são superavitários na produção de etanol.

\section{Referências}

AGÊNCIA NACIONAL DO PETRÓLEO, GÁS NATURAL E BIOCOMBUSTÍVEIS - ANP. Anuário Estatístico 2013. Disponível em: <http://www.anp.gov. br/?pg=66833>. Acesso em: 09 abr. 2014.

ALVES, J. S. e LIMA, R. C. Transmissão de preços entre mercados de açúcar espacialmente separados no Brasil: uma análise de co-integração. In: CONGRESSO DA SOCIEDADE BRASILEIRA DE ECONOMIA, ADMNISTRAÇÃO E SOCIOLOGIA RURAL, 48, 2010, Campo Grande-MS. Disponível em: <http://www. sober.org.br/palestra/15/1036.pdf >. Acesso em: 18 jan. 2012.

. Integração dos mercados de etanol no Brasil: uma análise de co-integração. In: CONGRESSO DA SOCIEDADE BRASILEIRA DE ECONOMIA, ADMNISTRAÇÃO E SOCIOLOGIA RURAL, 49, 2011, Belo Horizonte. Anais eletrônicos... Belo Horizonte, 2004.

ASSOCIAÇÃO NACIONAL DOS FABRICANTES DE VEÍCULOS AUTOMOTORES - ANFAVEA. Anuário Estatístico da Indústria Automobilística do Brasil 2013. Disponível em: <http://www.anfavea.com.br/anuario. html>. Acesso em: 12 jun. 2013.

BARRET, C. B. Measuring Integration and Efficiency in International Agricultural Markets. Review of Agricultural Economics, Salonica, v. 23, n. 1, p. 19-32, 2001.

BLOCK, A. S., CORONEL, D. A. e VELOSO, G. Análise da transmissão de preços no setor sucroalcooleiro brasileiro. Revista Eletrônica de Estratégia \& Negócios, Florianópolis, v. 5, n. 2, p. 120-137, 2012.
BORGES, S. L. Integração espacial dos estados produtores de açúcar no Brasil e o mercado internacional. 2010. 87p. Dissertação (Mestrado em Economia Aplicada) Universidade Federal de Viçosa, Viçosa, 2010.

BUENO, R. L. S. Econometria de séries temporais. São Paulo: Cengage Learning, 2008. 320p.

CASTRO, S. S. et al. A expansão da cana-de-açúcar no cerrado e no estado de Goiás: elementos para uma análise espacial do processo. Boletim Goiano de Geografia, Goiânia, v. 30, n. 1, p. 171-191, 2010.

CHIODI, L. Integração espacial no mercado brasileiro de milho. 2006. 90p. Dissertação (Mestrado em Economia Aplicada) - Escola Superior de Agricultura "Luiz de Queiroz", Universidade de São Paulo, Piracicaba, 2006.

DUNHAM, F. B., FLECK, D. L. e BOMTEMPO, J. V. A estruturação do sistema produção e inovação sucroalcooleiro como base para o Proálcool. Revista Brasileira de Inovação, Campinas, v. 10, n. 1, p. 35-72, jan.jun. 2011.

ELLIOTT, G., ROTHENBERG, T.J. e STOCK, J.H. Efficient tests for an autoregressive unit root. Econometrica, Chicago, v. 64, n. 4, p. 813-836, 1996.

ENDERS, W. Applied econometric time series. 3. ed. New York: John Wiley, 2010. 517p.

ENGLE, R. F. e GRANGER, C. W. J. Co-integration and error correction representation, estimation and testing. Econometrica, Chicago, v. 55, n. 2, p. 257-276, 1987.

FACKLER, P. L. e GOODWIN, B. K. Spatial price analysis. In: GARDNER, B. L. e RAUSSER, G. C. (Ed.). Handbook of Agricultural Economics. Amsterdam: NorthHolland Press, 2001, cap. 17, v. 1B, p. 971-1024.

GAMARRA, J. E. T. e WAQUIL, P. Análise da transmissão de preços entre os mercados do etanol e da gasolina desde o lançamento dos carros flex-fuel no mercado brasileiro. In: CONGRESSO DA SOCIEDADE BRASILEIRA DE ECONOMIA, ADMNISTRAÇÃO E SOCIOLOGIA RURAL, 47., 2009, Porto Alegre. Anais eletrônicos... Porto Alegre, 2009. Disponível em: <http:// www.sober.org.br/palestra/13/767.pdf > . Acesso em: 14 abr. 2010.

GOODWIN, B. K. e PIGGOTT, N. E. Spatial market integration in the presence of threshold effects. American Journal of Agricultural Economics, Salt Lake City, v. 83, n. 2, p. 630-637, 1999.

GUIMARÃES, F. L. Preços de etanol no Brasil: uma análise espacial. 2011. 126p. Dissertação (Mestrado em Agroenergia) - Escola de Economia de São Paulo, da Fundação Getúlio Vargas - EESP/FGV, São Paulo, 2011. 
HAMILTON, J. D. Time Series Analysis. Princeton: Princeton University Press, 1994. 820 p.

HARRIS, R. I. D. Using cointegration analysis in econometric modelling. London: Prentice Hall/Harvester Wheatsheat, 1995. 176p.

JOHANSEN, S. Statistical analysis of cointegration vectors. Journal of Economics Dynamics and Control, Amsterdam, v. 12, n. 2/3, p. 231-254, 1988.

. e JUSELIUS, K. Testing structural hypotheses in a multivariate cointegration analysis of the PPP and the UIP for UK. Journal of Econometrics, Amsterdam, v. 53, n. 1/3, p. 211-244, 1992.

KRUGMAN, P. R. e OBSTFELD, M. Economia Internacional: teoria e política. 6. ed. São Paulo: Addson Wesley, 2005. 558p.

MARCOLIN, N. Era quase aguardente. FAPESP on line, 2008. Disponível em: <http://www.revistapesquisa. fapesp.br/?art $=3468 \& b d=1 \& p g=1 \& l g>$. Acesso em: 17 set. 2012.

MEYER, J. Measuring market integration in the presence of transaction costs - a threshold vector error correction approach. Agricultural Economics, Blackwell, v. 31, p. 327-334, 2004.

MINISTÉRIO DA AGRICULTURA, PECUÁRIA E ABASTECIMENTO-MAPA.Usinasedestilarias cadastradas, 2013. Disponível em: <http://www.agricultura.gov.br/ desenvolvimento-sustentavel/agroenergia/orientacoestecnicas>. Acesso em: 9 jan. 2014.

MORAES, M. A. F. D. A desregulamentação do setor sucroalcooleiro do Brasil. Americana: Caminho Editorial, 2000. 238p.

MORETTIN, P. A. e TOLOI, C. M. C. Análise de séries temporais. São Paulo: Edgard Blücher, 2004. 535p.
NAKANE, M. I. Testes de exogeneidade fraca e de superoxogeneidade para a demanda por moeda no Brasil. $18^{\mathbf{o}}$ Prêmio BNDES de Economia,1994. 165p.

NG, S. e PERRON, P. Lag length selection and the construction of unit root tests with good size and power. Econometrica, Chicago, v. 69, n. 6, p. 1519-1554, nov. 2001.

OSTERWALD-LENUM, M. A Note with Quantiles of the Asymptotic Distribution of the Maximum Likelihood Cointegration Rank Test Statistic. Oxford Bulletin of Economics and Statistics, Oxford, v. 54, p. 461472, 1992.

PINDYCK, R. S. e RUBINFELD, D. L. Econometria: modelos e previsões. Rio de Janeiro: Elsevier, 2004. 760 p.

RAPSOMANIKIS, G., HALLAM, D. e CONFORTI, P. Market integration and price transmission in selected food and cash crop markets of developing countries: review and applications. In: Food and Agriculture Organization of the United Nations - FAO (Org.). COMMODITY MARKET REVIEW, 2003-2004. Roma, 2003. p. 51-76.

SERIGATI, F., AZEVEDO, P. F. e MARGARIDO, M. A. How integrated are the main markets of ethanol. In: ENCONTRO NACIONAL DE ECONOMIA, 40., 2012, Recife-PE. Anais eletrônicos... Recife-PE, 2012. Disponível em: <http://www.anpec.org.br/ encontro/2012/inscricao/files_I/i10-96974ce01864bb7d2 b7cd5454d831613.pdf > . Acesso em: 17 jan. 2013.

SHIKIDA, P. F. Expansão canavieira no Centro-oeste: limites e potencialidades. Revista de Política Agrícola, Brasília, v. 22, n. 2, p. 122-137, abr.jun. 2013.

SZMRECSÁNYI, T. O planejamento da agroindústria canavieira no Brasil: 1930-1975. São Paulo: Hucitec, 1979. 540 p. 
Tabela 1A. Teste sobre a perfeita integração sem restrições aos demais parâmetros

\begin{tabular}{cc}
\hline$H_{0}$ & Razão de Verossimilhança \\
\hline$\beta_{\mathrm{GO}}=-\beta_{\mathrm{MT}}$ & $54.537^{* *}$ \\
$\beta_{\mathrm{GO}}=-\beta_{\mathrm{MS}}$ & $43.421^{* *}$ \\
$\beta_{\mathrm{GO}}=-\beta_{\mathrm{MG}}$ & $50.795^{* *}$ \\
$\beta_{\mathrm{GO}}=-\beta_{\mathrm{PR}}$ & $44.338^{* *}$ \\
$\beta_{\mathrm{GO}}=-\beta_{\mathrm{SP}}$ & $79.722^{* *}$ \\
$\beta_{\mathrm{GO}}=-\beta_{\mathrm{AL}}$ & $21.322^{* *}$ \\
$\beta_{\mathrm{GO}}=-\beta_{\mathrm{PE}}$ & $48.041^{* *}$ \\
$\beta_{\mathrm{MT}}=-\beta_{\mathrm{MS}}$ & $50.668^{* *}$ \\
$\beta_{\mathrm{MT}}=-\beta_{\mathrm{MG}}$ & $46.778^{* *}$ \\
$\beta_{\mathrm{MT}}=-\beta_{\mathrm{PR}}$ & $56.466^{* *}$ \\
$\beta_{\mathrm{MT}}=-\beta_{\mathrm{SP}}$ & $87.412^{* *}$ \\
$\beta_{\mathrm{MT}}=-\beta_{\mathrm{AL}}$ & $30.492^{* *}$ \\
$\beta_{\mathrm{MT}}=-\beta_{\mathrm{PE}}$ & $35.146^{* *}$ \\
$\beta_{\mathrm{MS}}=-\beta_{\mathrm{MG}}$ & $58.948^{* *}$ \\
$\beta_{\mathrm{MS}}=-\beta_{\mathrm{PR}}$ & $65.166^{* *}$ \\
$\beta_{\mathrm{MS}}=-\beta_{\mathrm{SP}}$ & $59.900^{* *}$ \\
$\beta_{\mathrm{MS}}=-\beta_{\mathrm{AL}}$ & $47.004^{* *}$ \\
$\beta_{\mathrm{MS}}=-\beta_{\mathrm{PE}}$ & $47.698^{* *}$ \\
$\beta_{\mathrm{MG}}=-\beta_{\mathrm{PR}}$ & $62.980^{* *}$ \\
$\beta_{\mathrm{MG}}=-\beta_{\mathrm{SP}}$ & $58.435^{* *}$ \\
$\beta_{\mathrm{MG}}=-\beta_{\mathrm{AL}}$ & $52.828^{* *}$ \\
$\beta_{\mathrm{MG}}=-\beta_{\mathrm{PE}}$ & $46.454^{* *}$ \\
$\beta_{\mathrm{PR}}=-\beta_{\mathrm{SP}}$ & $48.730^{* *}$ \\
$\beta_{\mathrm{PR}}=-\beta_{\mathrm{AL}}$ & $55.914^{* *}$ \\
$\beta_{\mathrm{PR}}=-\beta_{\mathrm{PE}}$ & $39.726^{* *}$ \\
$\beta_{\mathrm{SP}}=-\beta_{\mathrm{AL}}$ & $76.455^{* *}$ \\
$\beta_{\mathrm{SP}}=-\beta_{\mathrm{PE}}$ \\
$\beta_{\mathrm{AL}}=-\beta_{\mathrm{PE}}$ \\
\hline $\mathrm{D}$ & $74.401^{* *}$ \\
& $20.579^{* *}$ \\
\hline & \\
\hline
\end{tabular}

Nota: Dois asteriscos indicam rejeição da hipótese de perfeita integração a um nível de significância de $10 \%$ - Valor Crítico $\chi^{2}(10 \%)$ 12,02.

Fonte: Elaborado pelos autores com dados da pesquisa.
Tabela 2A. Teste sobre a perfeita integração com restrições aos demais parâmetros

\begin{tabular}{cc}
\hline$H_{0}$ & Razão de Verossimilhança \\
\hline$\beta_{\mathrm{GO}}=-\beta_{\mathrm{MT}}$ & $7.203^{* *}$ \\
$\beta_{\mathrm{GO}}=-\beta_{\mathrm{MS}}$ & $8.009^{* *}$ \\
$\beta_{\mathrm{GO}}=-\beta_{\mathrm{MG}}$ & 2.609 \\
$\beta_{\mathrm{GO}}=-\beta_{\mathrm{PR}}$ & 2.172 \\
$\beta_{\mathrm{GO}}=-\beta_{\mathrm{SP}}$ & 3.092 \\
$\beta_{\mathrm{GO}}=-\beta_{\mathrm{AL}}$ & $5.057^{* *}$ \\
$\beta_{\mathrm{GO}}=-\beta_{\mathrm{PE}}$ & $5.410^{* *}$ \\
$\beta_{\mathrm{MT}}=-\beta_{\mathrm{MS}}$ & $8.939^{* *}$ \\
$\beta_{\mathrm{MT}}=-\beta_{\mathrm{MG}}$ & $8.210^{* *}$ \\
$\beta_{\mathrm{MT}}=-\beta_{\mathrm{PR}}$ & $6.909^{* *}$ \\
$\beta_{\mathrm{MT}}=-\beta_{\mathrm{SP}}$ & $7.149^{* *}$ \\
$\beta_{\mathrm{MT}}=-\beta_{\mathrm{AL}}$ & $8.735^{* *}$ \\
$\beta_{\mathrm{MT}}=-\beta_{\mathrm{PE}}$ & $9.090^{* *}$ \\
$\beta_{\mathrm{MS}}=-\beta_{\mathrm{MG}}$ & $10.524^{* *}$ \\
$\beta_{\mathrm{MS}}=-\beta_{\mathrm{PR}}$ & $12.092^{* *}$ \\
$\beta_{\mathrm{MS}}=-\beta_{\mathrm{SP}}$ & $14.224^{* *}$ \\
$\beta_{\mathrm{MS}}=-\beta_{\mathrm{AL}}$ & 4.355 \\
$\beta_{\mathrm{MS}}=-\beta_{\mathrm{PE}}$ & $4.860^{* *}$ \\
$\beta_{\mathrm{MG}}=-\beta_{\mathrm{PR}}$ & 1.428 \\
$\beta_{\mathrm{MG}}=-\beta_{\mathrm{SP}}$ & 4.456 \\
$\beta_{\mathrm{MG}}=-\beta_{\mathrm{AL}}$ & $5.460^{* *}$ \\
$\beta_{\mathrm{MG}}=-\beta_{\mathrm{PE}}$ & $6.032^{* *}$ \\
$\beta_{\mathrm{PR}}=-\beta_{\mathrm{SP}}$ & 4.579 \\
$\beta_{\mathrm{PR}}=-\beta_{\mathrm{AL}}$ & $5.462^{* *}$ \\
$\beta_{\mathrm{PR}}=-\beta_{\mathrm{PE}}$ & $5.985^{* *}$ \\
$\beta_{\mathrm{SP}}=-\beta_{\mathrm{AL}}$ & $6.019^{* *}$ \\
$\beta_{\mathrm{SP}}=-\beta_{\mathrm{PE}}$ & $6.482^{* *}$ \\
$\beta_{\mathrm{AL}}=-\beta_{\mathrm{PE}}$ & 1.528 \\
\hline $\mathrm{D}$ &
\end{tabular}

Nota: Dois asteriscos indicam rejeição da hipótese de perfeita integração a um nível de significância de $10 \%$ - Valor Crítico $\chi_{2}(10 \%)$ 4,60.

Fonte: Elaborado pelos autores com dados da pesquisa. 
